gressive cardiac enlargement usually occurs. Mural thrombi overlying damaged endocardium are common and embolic lesions from these may result. There is never a true valvular endocarditis although fibrosis of the papillary muscles or chordae tendineae may lead to incompetence of the mitral and the tricuspid valves (Brink \& Weber, 1963). The subendocardial fibrosis which is the essential feature of this condition produces a pearly-white thickening of the endocardium which histologically consists of fibrous tissue with little or no increase in elastic fibres. No true vascular lesions of polyarteritic type are found.

It is possible that Löffler's Syndrome (Löffler, 1932) is the benign counterpart of this condition, the lung involvement being self-limiting and the heart escaping damage. In our case pulmonary infiltration was present at an early stage of the disease and it is possible that this resulted in the interlobular fibrosis found at necropsy. It is interesting that the marked eosinophilic infiltration in the biopsy specimen of liver was not present in the necropsy sections. These appearances were so striking in life that the possibility of a leukaemic infiltration was considered, but this interpretation was not supported by the marrow findings. The disappearance of the infiltration as part of the natural progression of the disease seems likely, and Hoffman, Rosenbaum \& Genovese (1955) found a normal liver biopsy in their patient despite a pronounced blood eosinophilia.

The aetiology of Löffler's disease is unknown. On the basis of the eosinophilia an allergic mechanism is usually assumed. Whether the eosinophilic infiltration has a fibrogenic effect on the endocardium and myocardium or whether the fibrosis is the direct result of an underlying pathogenic agent is not clear. The possibility of a self-perpetuating autoimmune process following primary damage to the heart cannot be excluded.

\section{References}

BRINK, A.J. \& WEBER, H.W. (1963) Fibroplastic parietal endocarditis with eosinophilia. Löffler's endocarditis. Amer. J. Med. 34, 52.

ENGLEFELDT, B. \& ZetTerströM, R. (1956) Disseminated eosinophilic collagen disease. Acta med. scand. 153, 337.

Hoffman, F.G., Rosenbaum, D. \& Genovese, P.D. (1955) Fibroplastic endocarditis with eosinophilia (Löffler's endocarditis parietalis fibroplastica). Case report and review of literature. Ann. intern. Med. 42, 668.

LENNOX, B. (1948) Acute parietal endocarditis in a case of status asthmaticus. A possible early stage of Löffler's endocarditis parietalis fibroplastica with eosinophilia. J. Path. Bact. 60, 621

LöfFLER, W. (1932) Zur Differential-Diagnose der Lungeninfiltrierungen. II. Uber Flüchtige Succedan-Infiltrate (mit Eosinophilie). Beitr. z. Klin. Tuberk. 79, 368.

LöFFLER, W. (1936) Endocarditis parietalis fibroplastica mit Bluteosinophilie. Schweiz. med. Wschr. 66, 817.

Mautner, L.S. \& Harris, F. (1966) Fibrosing endocarditis with eosinophilia. Canad. med. Ass. J. 95, 1201.

Pierce, L.E. Hosseinian, A.H. \& Constantine, A.B. (1967) Disseminated eosinophilic collagen disease. Blood, 29, 5400

Saphir, O. (1958) A Text on Systemic Pathology, Vol. 1 p. 58. Grune \& Stratton, New York and London.

Weiss-Carmine, S. (1957) Die Endocarditis parietalis fibroplastica mit Bluteosinophilie (Löffler) und ihre Stellung im Rahmen der Parietalendokardifibrosen. Schweiz. med. Wschr. 87, 890.

WIENER, M.J. \& KNIGHTS, E.M. (1957) Löffler's endocarditis parietalis fibroplastica with eosinophilia. Amer. Heart $J$. 53, 157.

\title{
Tricuspid incompetence due to right ventricular papillary muscle dysfunction
}

\author{
ANNE E. TATTERSFIELD \\ M.B., B.S., M.R.C.P. \\ Medical Registrar, Cardiothoracic Department, \\ Central Middlesex Hospital
}

\section{Summary}

There has recently been much interest in mitral incompetence as a result of papillary muscle damage in myocardial infarction. We report a case of tricuspid incompetence due to papillary muscle dysfunction following myocardial infarction involving the right ventricle.

\section{Case report}

A 61-year-old male office worker was ad- mitted to the Coronary Care Unit at Central Middlesex Hospital in April 1967 with a typical history of myocardial infarction. In 1961 his blood pressure had been noted to be $210 / 120$ $\mathrm{mmHg}$ but he had no past history of ischaemic or rheumatic heart disease.

On admission his pain had disappeared and he was neither cyanosed nor dyspnoeic, with warm extremities. The pulse was regular $(80 / \mathrm{min})$ apart from 1:5 ectopic beats and his blood 
pressure was $140 / 100$. There were no murmurs, no triple rhythm, no raised jugular venous pressure or oedema but a few crepitations were present at the lung bases. Fundi showed arteriolar tortuosity only. The liver was not enlarged and there were no other abnormal findings. The electrocardiogram showed changes of recent posterior infarction and a chest X-ray showed a large heart with some pulmonary vascular congestion.

He was treated with bed rest, oxygen and diuretics and with procainamide for his ventricular ectopic beats. A loud pericardial rub was noted on the 3rd day. Progress was satisfactory until the 4th day after admission when he had a cardiac arrest and was found to be in asystole, from which he was successfully resuscitated. In view of the frequent number of ventricular ectopic beats preceding this episode it was thought probable that ventricular fibrillation had preceded the asystole and his procainamide was therefore increased. He was also given anticoagulants at this stage.

After this episode it was noted that he had developed signs of gross tricuspid incompetence. The ECG showed sinus rhythm. His jugular veins showed very prominent ' $v$ ' waves, rising to the angle of the jaw with a very steep ' $y$ ' descent. The liver was now enlarged $5 \mathrm{~cm}$ below the costal margin and there was systolic pulsation. $\mathrm{He}$ was also noted to have a third heart sound but no murmur had developed.

He improved thereafter and his heart-size decreased on X-ray (Fig. 1). Signs of tricuspid incompetence persisted, however, despite increased doses of diuretics and digoxin. The ventricular ectopic beats ceased on increased doses of procainamide; sinus rhythm persisted. He was discharged to the general ward where, 14 days after his initial admission, he again developed ventricular fibrillation followed by asystole. Resuscitation was unsuccessful on this occasion.

\section{Necropsy}

The heart $(580 \mathrm{~g})$ showed haemorrhagic pericarditis, predominantly on the posterior surface. There was an old, fibrous, apical infarct involving the posterior wall of the left ventricle and most of the intraventricular septum. It extended to the posterior wall of the right ventricle and the associated papillary muscles of the tricuspid valve. The right atrium was enlarged but not infarcted. The valves were normal and the circumference of the tricuspid valve ring was $15 \mathrm{~cm}$. There is little information in the literature on the normal size: Roessle \& Roulet (1932) using the measurements of Kirch, relate the circum-

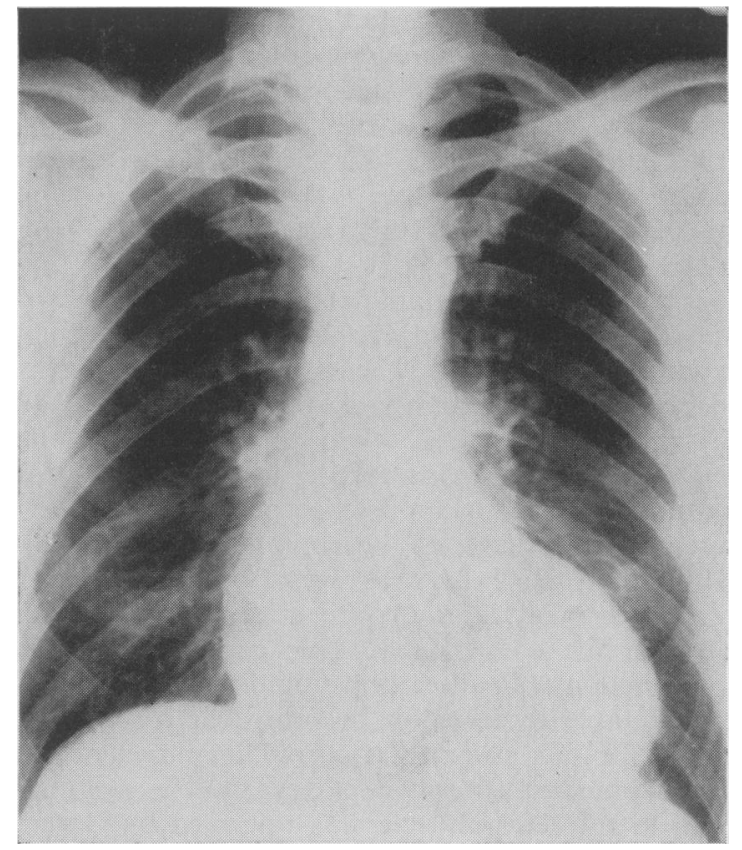

Fig. 1. Chest X-ray (portable film) 7 days after treatment showing reduction in cardiac size and improvement in pulmonary vascular congestion.

ference of the tricuspid valve to age. For a man of 60 the expected circumference would be about $12 \mathrm{~cm}$, but this series was not large and the normal range was not given. The authors point out that these measurements can be fallacious and depend, among other things, on the state of contraction of the myocardium, whether or not the heart has been preserved in formalin and on the observer. In this patient the circumference was measured after preservation in formalin. The right coronary artery was occluded up to $80 \%$ by atheroma with a long thrombus $(7 \mathrm{~cm})$ starting close to its ostium. The left coronary artery was atheromatous with old fibrous narrowing of the left descending branch.

Histology confirmed complete full-thickness infarction of the posterior wall of the right ventricle. The right ventricular posterior papillary muscles showed complete infarction and the anterior papillary muscles showed partial, non-fullthickness infarction.

The liver was enlarged (2000 g) and showed passive venous congestion.

\section{Discussion}

After myocardial infarction tricuspid incompetence appears to be a rare occurrence, apart from patients with severe congestive cardiac failure. Eisenberg \& Suyemoto (1964), reported 
one patient with tricuspid incompetence due to a ruptured papillary muscle after myocardial infarction. The higher incidence of left ventricular papillary muscle dysfunction reported (Heikkilä, 1967) must be largely due to the higher incidence of left ventricular infarction observed by various workers (Wartman \& Hellerstein, 1948; Zaus \& Kearns, 1952).

This patient had minimal dilatation of the tricuspid valve ring and the valves at post-mortem appeared competent. The neropsy impression is occasionally misleading as the valve ring may be larger during life, when the pressure in the right ventricle is increased. However, in this patient tricuspid incompetence persisted, although the clinical signs of heart failure were mild, although such failure as was present improved with treatment, and despite a decrease in heart size on the chest X-ray. This clinical course in conjunction with the autopsy findings make papillary muscle dysfunction the only tenable explanation for this patient's tricuspid incompetence.

The mechanism of papillary muscle dysfunction in the left ventricle was reviewed by Burch, De Pasquale \& Phillips (1963) and more recently by Raftery, Oakley \& Goodwin (1966). The very prominent ' $v$ ' waves and ' $y$ ' descent in the jugular veins of this patient accord well with the left atrial pressure tracings found in patients with left ventricular papillary muscle dysfunction (Raftery et al., 1966). The right atrium in this patient was presumably normal before the sudden development of tricuspid incompetence and the venous pressure excursions were not damped because the atrium was still relatively uncompliant.

Diagnosis of the cause of tricuspid incompetence is important. When due to papillary muscle dysfunction it should be amenable to surgical treatment as is mitral incompetence (Fluck et al., 1966). If this patient had survived with persistent tricuspid incompetence the question of prosthetic valve replacement would have been seriously considered.

\section{Acknowledgments}

I would like to thank Dr M. W. McNicol for help in prepreparing this paper and Dr R. A. B. Drury for assistance with the autopsy findings.

\section{References}

Burch, G.E., De Pasquale, N.P. \& Phillips, J.H. (1963) Clinical manifestations of papillary muscle dysfunction. Arch. intern. Med. 112, 112.

Eisenberg, S. \& SUyemoto, J. (1964) Rupture of a papillary muscle of the tricuspid valve following acute myocardial infarction. Circulation, 30, 588.

Fluck, D.C., Taubman, J.O., Cleland, W.P. \& Mounsey, J.P.D. (1966) Acute mitral incompetence after acute myocardial infarction, with successful early treatment by mitral valve prosthesis. Lancet, ii, 1052.

HeIKKILÄ, J. (1967) Mitral incompetence complicating acute myocardial infarction. Brit. Heart J. 29, 162.

RafTery, E.B., OAKley, C.M. \& Goodwin, J.F. (1966) Acute subvalvar mitral incompetence. Lancet, ii, 360.

Roessle, R. \& Roulet, F. (1932) Mass und Zahl in Dexô Pathologie. Springer, Berlin.

Wartman, W.B. \& Hellerstein, H.K. (1948) The incidence of heart disease in 2,000 consecutive autopsies. Ann. intern. Med. 28, 41.

ZAus, E.A. \& KEARNS, W.M., Jr. (1952) Massive infarction of the right ventricle and atrium. Circulation, 6, 593.

\title{
Intrahepatic granulomatous arteriopathy
}

\author{
H. Fox \\ M.D., M.C.Path. \\ M. H. Gleeson \\ M.B., Ch.B.
W. F. W. E. LOGAN
M.R.C.P. \\ Departments of Pathology and Cardiology, \\ University of Manchester and Manchester Royal Infirmary
}

\section{Summary}

The case history is detailed of a 55-year-old woman who was investigated for persistent pyrexia and anaemia. A liver biopsy specimen showed an unusual lesion of the small intrahepatic arteries. Many of these vessels showed circumferential replacement of their adventitial coat by a non-caseating granuloma whilst others showed localized granulomata focally interrupting the adventitial coat. The medial and intimal coats of the affected arteries were normal.
This was an intrahepatic granulomatous arteriopathy of unknown origin. The patient responded promptly and completely to steroid therapy.

\section{Introduction}

It is the purpose of this report to describe an unusual form of arteriopathy involving the intrahepatic vessels.

\section{Case report}

A woman, aged 55, was seen at Manchester 